Copyright (@ 2009 Institute of Electrical and electronics Engineers, Inc.

All Rights reserved.

Personal use of this material, including one hard copy reproduction, is permitted.

Permission to reprint, republish and/or distribute this material in whole or in part for any other purposes must be obtained from the IEEE.

For information on obtaining permission, send an e-mail message to stds-igr@ieee.org.

By choosing to view this document, you agree to all provisions of the copyright laws protecting it.

Individual documents posted on this site may carry slightly different copyright restrictions.

For specific document information, check the copyright notice at the beginning of each document. 


\title{
Strategic Procurement's Impact on Organisations and Prospects for Multi-Disciplinary Research
}

\author{
Dr Ananda Jeeva \\ Faculty of Business and Informatics, Central Queensland University \\ Queensland, Australia
}

Monday October 14, 2008

9:30-10:00

Symposium Hall at Meeting Hall

\begin{abstract}
Procurement and Supply Management strategies are becoming more vital in organisational strategic plans. Also there is an increase of demand and recognition for Chief Procurement Officers in large MNCs. Dr Jeeva will introduce the concept of procurement and supply management, and how the various schools and faculties can conduct multi-disciplinary research. The presentation will also look at some common theories and how they fit into the research context. This presentation intends to increase the awareness of the concepts of procurement and supply management. The understanding of procurement and supply concepts can lead to multi-disciplinary research between different faculties and schools. The presentation will also provide possible areas of multi-disciplinary areas of research between Procurement and: Law, Marketing, IT, IS, HRM, Engineering, Sciences, Agriculture and Accounting. This presentation encourages the formulation of the concept of procurement \& supply into their areas of specialisation.
\end{abstract}

Biography Dr Jeeva is a senior lecturer and researcher in procurement and supply in the Faculty of Business and Informatics at the Central Queensland University in Queensland Australia. Recently, he completed the design, development and delivery of an undergraduate Business degree in Procurement \& Supply Management. Previously he worked as a consultant and engineer. He was a member of the Steering Committee of The Chartered Institute of Purchasing and Supply for 2 years, helping to set the direction of education and increasing the profile of procurement practitioners in Australia. Dr Jeeva specialises in procurement and supply chain management and related activities in services and products. He has a total of 25 years industry experience. He has researched and presented papers at many industry conferences. Academically he holds a Bachelor of Commerce (Marketing \& Management) from Murdoch University and a Master of Business Administration from Curtin University of Technology. He is also an Electronics Engineer. He completed his $\mathrm{PhD}$ in Procurement Flexibility with a Supply Chain Management Perspective at Curtin University. 